\title{
PENGARUH JUMLAH FASA TERHADAP FREKUENSI KELUARAN PADA STEP DOWN CHOPPER
}

\author{
Achmad Mudawari \\ Jurusan Teknik Konversi Energi- Politeknik Negeri Bandung \\ Jl. Gegerkalong Hilir, Ds. Ciwaruga - Bandung 40551 \\ E-mail: mudawari@yahoo.com
}

\begin{abstract}
Abstrak
Chopper banyak dipergunakan sebagai power suply dan diharapkan riak keluarannya sekecil mungkin. Untuk mengurangi riak pada sisi keluaran chopper dapat dipasang tapis. Ukuran tapis dapat dipengaruhi oleh besar kecilnya frekuensi. Dalam artikel ini diusulkan cara untuk mempertinggi frekuensi keluaran tanpa mempertinggi frekuensi switching komponen elektroniknya. Dari hasil analisis maupun simulasi menunjukkan bahwa pada step down chopper dua fas a frekuensi arus keluaran besarnya dua kali frekuensi arus fasanya.
\end{abstract}

\section{PENDAHULUAN}

Chopper banyak dipergunakan sebagai power supply, oleh karena itu diharapkan riak keluarannya sekecil mungkin. Untuk mengurangi riak keluaran, pada sisi keluaran chopper dapat dipasang tapis. Besar kecilnya ukuran tapis dipengaruhi oleh besarnya amplitudo riak keluaran dan frekuensinya. Untuk memperkecil riak keluaran dapat dilakukan dengan mempertinggi frekuensi switching chopper dan atau memperbesar ukuran tapis. Salah satu cara untuk mempertinggi frekuensi keluaran tanpa mempertinggi frekuensi switching adalah dengan memperbanyak jumlah fasa dari chopper.

\section{BATASAN MASALAH}

Untuk mencapai tujuan penelitian, penulis perlu memberi batasan sebagai berikut.

a. Tidak membahas masalah pengaruh macam-macam beban

b. Tidak membahas rugi-rugi pada komponen

c. Pembahasan pada kondisi tunak.

d. Konduksi arus induktor tapis dianggap kontinyu.

\section{CHOPPER DUA FASA.}

Gambar 1 menampilkan skema rangkaian chopper dua fasa dengan induktor (L) dan
Kata kunci: DC Chopper, riak keluaran, frekuensi

kapasitor (C) sebagai filter keluaran. Pada prinsipnya chopper dua fasa mempunyai prinsip kerja yang sama dengan chopper satu fasa. Hanya saja pada chopper dua fasa mempunyai dua kondisi konduksi yang masing-masing saling tergeser sebesar 180 derajat listrik atau sebesar $\mathrm{T} / 2$.

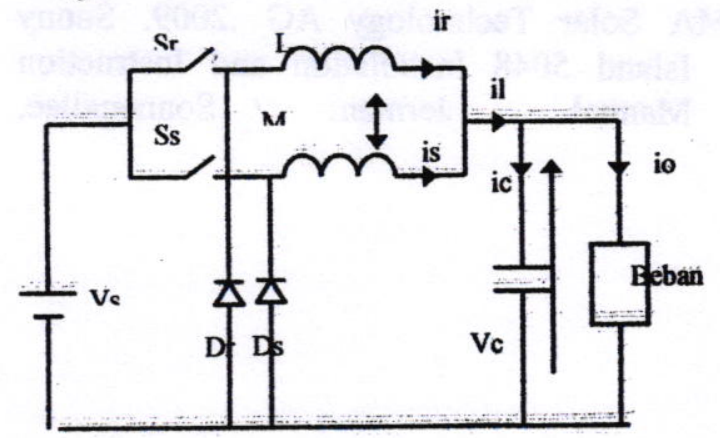

Gambar. 1 Gambar rangkaian chopper 2 fasa.

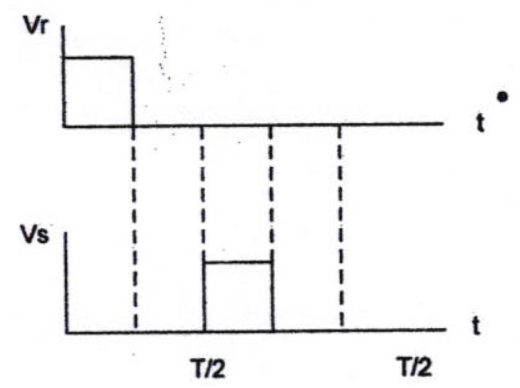

Gambar 2 Gelombang tegangan fasa untuk $0<\mathrm{D}<\mathrm{T} / 2$ 


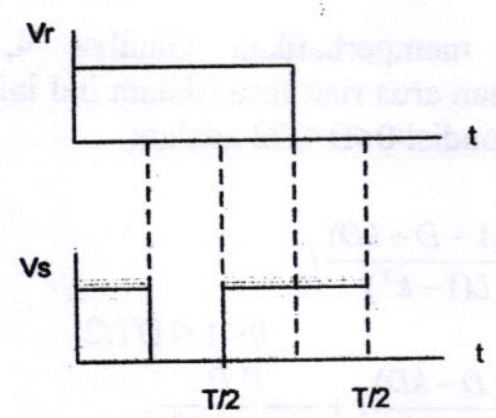

Gambar. 3 Gelombang tegangan fasa untuk $\mathrm{T} / 2<\mathrm{D}<\mathrm{T}$

Dengan memperhatikan Gambar 2 dan 3 dapat dilihat bahwa chopper dua fasa dapat terjadi beberapa kondisi konduksi dan tidak konduksinya saklar dan dioda, yaitu

a. Dua saklar konduksi dan dua dioda tidak konduksi

b. Satu saklar konduksi dan satu dioda konduksi

c. Dua saklar tidak konduksi dan dua dioda konduksi

Dengan demikian untuk $0<\mathrm{D}<1 / 2$ akan terjadi kondisi [b] dan [c], sedangkan untuk $1 / 2<\mathrm{D}<1$ akan terjadi kondisi [a] dan [b].

Tegangan fasa yang dirasakan masing-masing fasa pada chopper dua fasa akan dipengaruhi oleh ke tiga kondisi diatas.

\section{PERSAMAAN TEGANGAN}

Dengan memperhatikan Gambar 2 dan Gambar 3 maka persamaan tegangan fasa dapat dituliskan sebagai berikut:

$\left[\begin{array}{l}v_{r} \\ v_{s}\end{array}\right]=\left[\begin{array}{cc}R & 0 \\ 0 & R\end{array}\right]\left[\begin{array}{c}i_{r} \\ i_{s}\end{array}\right]+p \cdot\left[\begin{array}{cc}L & M \\ M & L\end{array}\right]\left[\begin{array}{c}i_{r} \\ i_{s}\end{array}\right]+\left[\begin{array}{l}v_{c} \\ v_{c}\end{array}\right](1)$

Keterangan:

$[v]=\left[\begin{array}{ll}v_{r} & v_{s}\end{array}\right]^{t}=$ tegangan fasa

$\mathbf{R}=$ Resistansi dari induktor tapis

$[i]=\left[\begin{array}{ll}i_{r} & i_{s}\end{array}\right]^{t} \quad=$ arus fasa

$\mathrm{p}=\mathrm{d} / \mathrm{dt}$

$\mathrm{L}=$ Induktansi diri induktor tapis

$\mathbf{M}=$ Induktansi bersama induktor tapis

$\left[v_{c}\right]=$ tegangan pada kapasitor tapis
Jika masing-masing komponen tegangan dan arus diuraikan menjadi komponen riak dan komponen rata-rata maka persamaan tegangan untuk komponen riaknya dapat dituliskan sebagai berikut:

$\left[\begin{array}{l}\tilde{v}_{r} \\ \tilde{v}_{s}\end{array}\right]=\left[\begin{array}{ll}R & 0 \\ 0 & R\end{array}\right]\left[\begin{array}{l}\tilde{i}_{r} \\ \tilde{i}_{s}\end{array}\right]+p \cdot\left[\begin{array}{cc}L & M \\ M & L\end{array}\right]\left[\begin{array}{c}\tilde{i}_{r} \\ \tilde{i}_{s}\end{array}\right]+\left[\begin{array}{c}\tilde{v}_{c} \\ \tilde{v}_{c}\end{array}\right]$

Apabila nilai R. $\tilde{i}$ dan $\tilde{v}_{c}$ sangat kecil dibanding p. $\tilde{i}$, maka $R . \tilde{i}$ dan $\tilde{v}_{c}$ dapat diabaikan sehingga persamaan tegangan untuk komponen riaknya adalah:

$$
\left[\begin{array}{c}
\tilde{v}_{r} \\
\tilde{v}_{s}
\end{array}\right]=p \cdot\left[\begin{array}{cc}
L & M \\
M & L
\end{array}\right]\left[\begin{array}{l}
\tilde{i}_{r} \\
\tilde{i}_{s}
\end{array}\right]
$$

Kemudian jika persamaan-persamaan diatas diturunkan untuk mendapatkan kemiringan arus riak pada masing-masing fasa, maka diperoleh:

$p \cdot\left[\begin{array}{l}\tilde{i}_{r} \\ \tilde{i}_{s}\end{array}\right]=\left[\begin{array}{cc}L & M \\ M & L\end{array}\right]^{-1}\left[\begin{array}{l}\tilde{v}_{r} \\ \tilde{v}_{s}\end{array}\right]$

dimana:

$\left[\begin{array}{l}\tilde{v}_{r} \\ \tilde{v}_{s}\end{array}\right]=\left[\begin{array}{l}v_{r} \\ v_{s}\end{array}\right]-\left[\begin{array}{l}\bar{v}_{r} \\ \bar{v}_{s}\end{array}\right]$

\section{Kemiringan arus riak fasa untuk $0<\mathrm{D}<1 / 2$}

Kemiringan arus riak fasa dapat diturunkan dari persamaan (4) dan (5). Jika $M=k . L$, maka persamaan di atas dapat ditulis sebagai berikut:

$$
p \cdot\left[\begin{array}{l}
\tilde{i}_{r} \\
\tilde{i_{s}}
\end{array}\right]=\frac{1}{L^{2}-M^{2}}\left[\begin{array}{cc}
L & -M \\
-M & L
\end{array}\right]\left[\begin{array}{l}
v_{r}-\bar{v}_{r} \\
v_{s}-\bar{v}_{s}
\end{array}\right]
$$

Untuk menggambarkan gelombang arus riak fasa dapat diperoleh dengan menggambarkan gelombang arus fasa yang masih mengandung komponen riak dan komponen rata-rata kemudian dikurangi dengan komponen rataratanya, maka bentuk gelombang arus riak fasa dapat ditampilkan seperti terlihat pada Gambar 4. 

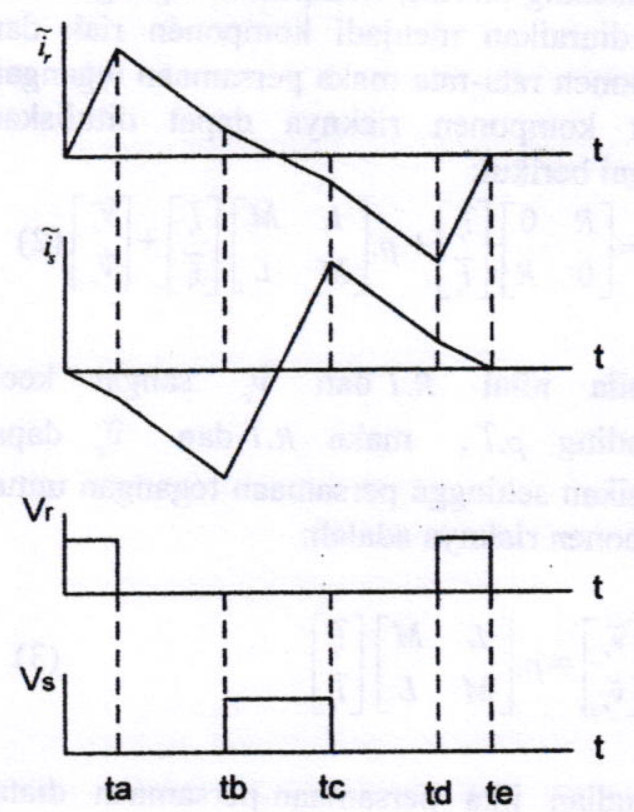

keterangan:
ta $=\mathrm{DT} / 2$ tc $=(1+D) T / 2 \quad$ te $=$
$\mathrm{T}$
$\mathrm{tb}=(1-\mathrm{D}) \mathrm{T} / 2 \quad \mathrm{td}=(2-\mathrm{D}) \mathrm{T} / 2$

Gambar 4 Gelombang arus riak fasa untuk $0<\mathrm{D}<\mathrm{T} / 2$

Dengan memperhatikan matrik konstanta tegangan dan dengan mengingat bahwa $\bar{v}=D . V s$, maka kemiringan arus riak fasa untuk fasa $r$ pada $0<\mathrm{D}<\mathrm{T} / 2$ adalah sebagai berikut:

$\tilde{i}_{-}=\frac{V_{s}(k D+D-1)}{L\left(1-k^{2}\right)} \quad 0<\mathrm{t}<\mathrm{DT} / 2$ (7)

$\tilde{i}_{r}=\frac{V_{s}(k D-D)}{L\left(1-k^{2}\right)}$

$\mathrm{DT} / 2<\mathrm{t}<\mathrm{T} / 2(1-\mathrm{D})$

(8)

$\tilde{i}_{,}=\frac{V_{s}(k D-D-k)}{L\left(1-k^{2}\right)} \quad \mathrm{T} / 2(1-\mathrm{D})<\mathrm{t}<\mathrm{T} / 2(1+\mathrm{D})$ (9)

$\tilde{i}_{.}=\frac{V_{s}(k D-D)}{L\left(1-k^{2}\right)} \quad \mathrm{T} / 2(1+\mathrm{D})<\mathrm{t}<\mathrm{T} / 2(2-\mathrm{D})$ (10)

$\tilde{i}_{r}=\frac{V_{s}(k D+D-1)}{L\left(1-k^{2}\right)} \quad \mathrm{T} / 2(2-\mathrm{D})<\mathrm{t}<\mathrm{T}$

Persamaan arus riak fasa untuk $0<D<1 / 2$

Dengan menggunakan persamaan kemiringan arus riak fasa persamaan (7) sampai (11) dan dengan memperhatikan Gambar 4, maka persamaan arus riak fasa (dalam hal ini fasa $\mathbf{r}$ ) untuk kondisi $0<\mathrm{D}<\mathrm{T} / 2$ adalah:

$$
\begin{gathered}
\tilde{i}_{r}=\frac{V_{s}(1-D+k D)}{L\left(1-k^{2}\right)} t \\
\tilde{i}_{r}=-\frac{V_{s}(D-k D)}{L\left(1-k^{2}\right)} t+\frac{V_{s} D}{2 f L\left(1-k^{2}\right)} \\
\tilde{i}_{r}=-\frac{V_{s}(D+k-k D)}{L\left(1-k^{2}\right)} t+\frac{V_{s}(D+k-k D)}{2 f L\left(1-k^{2}\right)} \\
\tilde{i}_{r}=-\frac{V_{s}(D-k D)}{L\left(1-k^{2}\right)} t+\frac{V_{s}(D-2 k D)}{2 f L\left(1-k^{2}\right)} \\
\mathrm{T} / 2(1+\mathrm{D})<\mathrm{T} / 2(1+\mathrm{T} / 2(2-\mathrm{D})(14) \\
\tilde{i}_{r}=\frac{V_{s}(1-D+k D)}{L\left(1-k^{2}\right)} t+\frac{V_{s}(-1+D-k D)}{f L\left(1-k^{2}\right)} \\
\mathrm{T} / 2(2-\mathrm{D})<\mathrm{t}<\mathrm{T} / 2
\end{gathered}
$$

\section{Arus riak beban untuk $0<\mathrm{D}<1 / 2$}

Dari Gambar 1 terlihat bahwa arus beban merupakan jumlah dari arus pada masingmasing fasanya.

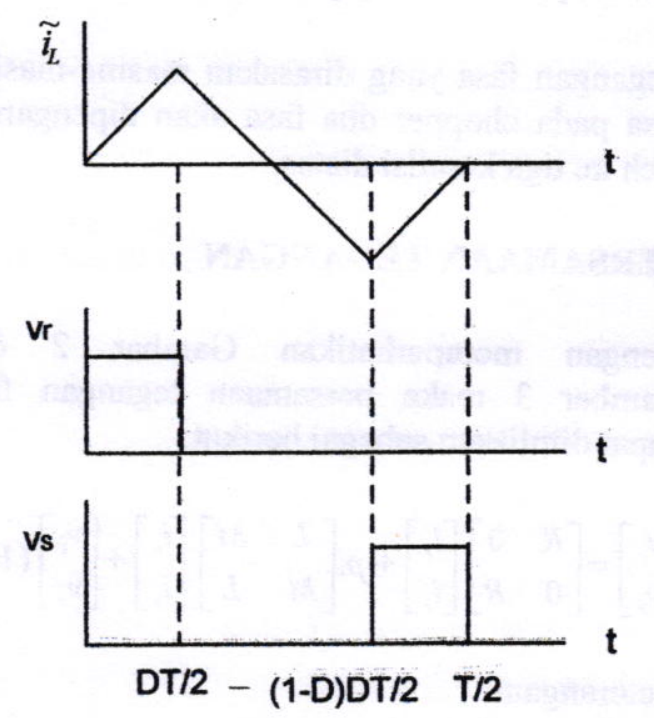

Gambar 5 Gelombang arus riak beban untuk $0<\mathrm{D}<1 / 2$

$$
\begin{aligned}
& i_{L}=i_{r}+i_{s} \\
& \left(\bar{i}_{L}+\tilde{i}_{L}\right)=\left(\bar{i}_{r}+\tilde{i}_{r}\right)+\left(\bar{i}_{s}+\tilde{i}_{s}\right) \\
& \bar{i}_{L}=\bar{i}_{r}+\bar{i}_{s} \\
& \tilde{i}_{L}=\tilde{i}_{r}+\tilde{i}_{s}
\end{aligned}
$$


Gambar 5 memperlihatkan tingginya frekuensi arus beban adalah dua kali dari frekuensi arus fasanya, maka dalam satu perioda akan terjadi dua kali gelombang arus beban. Oleh karena itu dalam menganalisis arus beban diambil satu gelombang saja yaitu selama $T / 2$. Besarnya arus beban dapat dicari dengan menjumlahkan arus-arus fasanya dan diperoleh persamaan berikut:

$\tilde{i}_{i}=\frac{V_{s}(1-2 D)}{\dot{L}(1+k)} t$

$0<\mathrm{t}<\mathrm{DT} / 2$

$\tilde{i}_{i}=-\frac{2 V_{s} D}{L(1+k)} t+\frac{V_{s} D}{2 f L(1+k)}$

DT $/ 2<\mathrm{t}<\mathrm{T} / 2(1-\mathrm{D})$

$\tilde{i}_{i}=\frac{V_{s}(1-2 D)}{L(1+k)} t-\frac{V_{s}(1-2 D)}{2 f L(1+k)}$

$\mathrm{T} / 2(1-\mathrm{D})<\mathrm{t}<\mathrm{T} / 2$

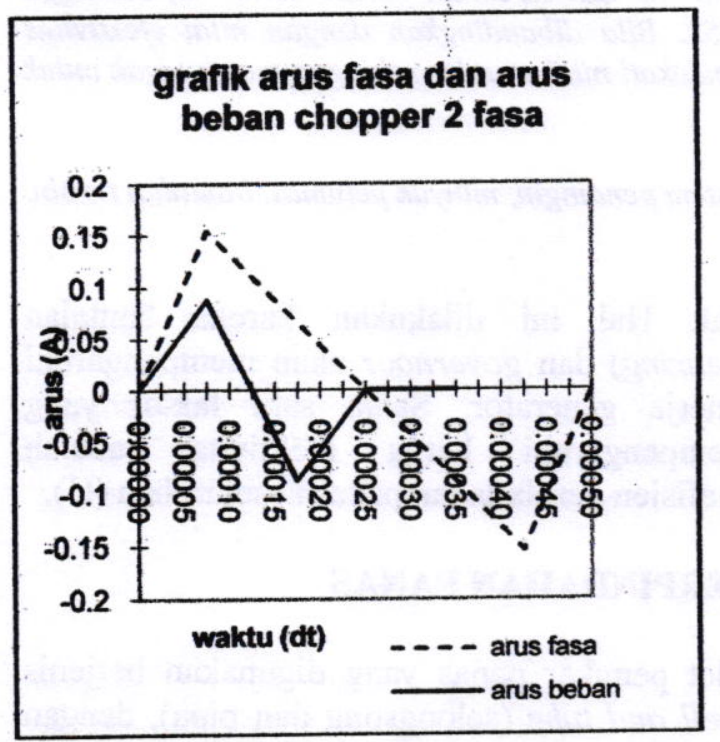

Gambar 6 Grafik simulasi arus fasa dan arus beban untuk $0<\mathrm{D}<1 / 2$

Dari grafik hasil simulasi (Gambar 6) terlihat bahwa dalam satu perioda swichting saklar elektronik baik untuk fasa $r$ maupun fasa $s$ terdapat dua perioda gelombang arus beban. $\mathrm{Hal}$ ini menunjukkan bahwa besarnya frekuensi keluaran akan menjadi dua kali lipat frekuensi arus fasanya. Selain itu besarnya riak keluaran juga terlihat semakin kecil, sudah barang tentu ukuran filter yang digunakanpun juga akan semakin kecil. Namun demikian masalah ukuran filter masih perlu untuk dianalisis lebih lanjut.

\section{KESIMPULAN}

Dari hasil analisis maupun simulasi menunjukkan bahwa pada step down chopper dua fasa frekuensi arus keluaran besarnya dua kali frekuensi arus fasanya.

\section{DAFTAR PUSTAKA}

Abaraham I.Pressman, Switcing Power Electronic Design, Mc Graw Hill International Eddition, 1992.

Kield Thorborg, Power Electronis, Prentice Hall, 1988.

Control in Power Electronics, Selected Problem, 2002.

MD Singh second edition, Mc Graw Hill, 2007. 